\title{
Nurse led venesection: a quality improvement project
}

\author{
Chandni Patel, Dafydd Morgan \\ Royal Free Trust, London
}

\begin{abstract}
Venesection is a widely practised procedure, involving the removal of a unit of blood in order to treat haemochromatosis and polycythaemia. It is still well regarded due to a lack of better alternatives and a small side effect profile. At Barnet General Hospital, venesection has recently been a physician led service, unlike its neighbouring hospital at Chase Farm Hospital, which has a well run nurse led service. The current service being run at Barnet Hospital was beset with problems, including delays in service provision and discharge, using junior doctors who may not be comfortable with or have knowledge of pre and post procedure checks. Furthermore, the medical day treatment unit is comprised of highly skilled nurses. $100 \%$ of nursing staff felt comfortable gaining venous access, but none had any formal training. Following a practical tutorial, followed by formal teaching, the nurses now run the venesection service. This has been done at no cost to the hospital, has sped up discharges and this has subsequently led to the capacity of the unit to venesect patients to increase by $100 \%$.
\end{abstract}

\section{Problem}

Venesection is predominantly a nurse led service across the United kingdom, being performed at medical centres with little physician assistance.[1-7] However, venesection has been physician led at Barnet General Hospital for the past two years; the service being split between the junior doctors from both gastroenterology and haematology departments. This service is provided on the medical day treatment unit, compromised of highly experienced nursing staff who routinely cannulate patients and administer blood products, usually in the absence of physicians.

The doctor led service has inherently had its problems. Due to venesection being performed by doctors routinely working on medical wards, there are frequently delays in both starting the venesection list and discharging patients. Due to the removal of doctors from their base wards, this can lead to staffing shortages and pressures for those remaining on the haematology and gastroenterology wards. The doctor led venesection programme did not require any formal training beforehand, leading to poor knowledge and practice, exacerbated by the changing rota and high turnover of doctors every four months. This high turnover of doctors also leads to issues regarding continuity of care and recognition of technically challenging patients.

\section{Background}

Venesection, known historically as "blood-letting", is an ancient procedure practiced for nearly two millenia. It consists of the removal of blood from a patient for therapeutic purposes. [8-10] It is now less commonly practiced, with fewer indications. It's indications include haemochromatosis, polycythaemia vera, and porphyria cutanea tarda.[11-15]

\section{Baseline measurement}

In order to improve the venesection service, a questionnaire was distributed to both nurses and doctors working on the medical day treatment unit. This included open and closed questions concerning clinical competency and knowledge of procedures. Two measurement outcomes were identified form our study:

1. Confidence gaining venous access: of the questionnaire respondents, $100 \%$ of nurses felt confident identifying sites for venesection, whereas only $80 \%$ of doctors felt confident.

2. Confidence with the practical aspects of venesection, including pre and post procedure checks i.e. blood parameters: $75 \%$ of nurses and $80 \%$ of doctors were aware of procedural checks for venesection.

See supplementary file: ds5436.docx - "Questionnaire \& Figures"

\section{Design}

When considering the many problems faced with the doctor led venesection service, a number of interventions were considered. These included hiring a specialist nurse for venesection services and a rolling rota for doctors. However, both are beset with problems, mainly involving increasing expenses and staffing issues. The most definitive solution to our problems was to train the already existing pool of highly experienced nurses on the medical day treatment unit.

There are many advantages to this intervention. Training the nurses already on the ward would come at no additional cost. The continuous and long term presence of these nurses on the medical day unit also ensures continuity of care and prompt venesection, reducing waiting times and discharges. This subsequently leads to improved patient satisfaction. Furthermore, doctors on the medical wards are no longer required, consequently improving staffing numbers on the haematology and gastroenterology wards.

This solution was designed using a similar template successfully exercised at another hospital in the trust; being coupled with discussions amongst the existing nursing staff and a meeting with 
senior clinicians, who ratified the idea.

\section{Strategy}

PDSA cycle 1: A questionnaire was disseminated to all members of staff about improving the venesection service. This highlighted that nursing staff had not been trained and were therefore not comfortable in venesecting. They were subsequently trained by the senior band 7 nurse, and once competent were transitioned into venesecting patients. We hoped this would be a smooth transition, however within a two week period it was noted that doctors were still being bleeped to attend the day treatment unit on Tuesday and Thursday afternoons. This was due to confidence issues.

PDSA cycle 2: Nurses were still uncomfortable venesecting. From speaking to them and redistributing the questionnaire, we recognised that this was due to them feeling uncomfortable with recognising and dealing with complications of venesection. Although they had not encountered any complications, they were concerned about if/when they did, what would they then do. We therefore planned to hold a training session and produce a presentation which they could access at any time. A detailed powerpoint presentation chronicling the potential complications of venesection and how to overcome these problems were placed on the hospital intranet, available to all members of staff.

\section{Post-measurement}

Anonymous questionnaires were distributed to all staff members on the medical day treatment unit. They were completed by the four nurses working on the medical day treatment unit, and the five junior doctors who initially comprised the venesection service (two from haematology and three from gastroenterology).

The questionnaire demonstrated some interesting findings.

A higher percentage of nurses than doctors were more comfortable gaining venous access at the beginning of the study (100\% versus $80 \%)$.

$75 \%$ of nurses were uncomfortable with the practical aspects of venesection, versus $80 \%$ of doctors.

Although both professional groups understood why venesection was performed, neither knew there were specific protocols regarding pre and post procedure checks. They did not know there were specific blood result parameters which needed to be checked prior to proceeding with venesection.

Open questions were added to the end of the questionnaire, allowing respondents to express any underlying problems with the service and suggestions for improvement.

These highlighted that doctors were more concerned about time taken off their base ward, lack of formal training, and patients' frustration with delayed venesection/discharge times.
From a nursing perspective the main issue was not being trained to venesect, and frustration waiting for doctors to arrive.

Having implemented our changes to the venesection service, including educating the nurses and ensuring procedural competencies, the questionnaire was redistributed.

The second questionnaire yielded $100 \%$ confidence rates both gaining venous access and venesecting; improved from the first survey. Improved knowledge and confidence was noted amongst the doctors responses, reporting fewer visits to the medical day treatment unit, owing mainly to complications (e.g. syncopal episodes). Nursing staff reported improved patient satisfaction and reduced waiting times. Furthermore, nurses felt more confident venesection, requiring little, if any, assistance from doctors. If escalation was required doctors were readily available, and they felt confident in escalating to a more senior member of staff. On occasions consultants had been called to review blood results.

See supplementary file: ds5437.docx - "Results"

\section{Lessons and limitations}

Nurses were initially very apprehensive about taking over the venesection service, owing to a lack of knowledge about the practical aspects. We had to explain that blood product infusions had more significant side effect profiles than venesecting. This had to be reinforced from a senior level, i.e. consultants. A short powerpoint presentation also helped reduce anxiety about venesecting. Although our study yielded positive findings, some limitations were identified.

The cohort was small, but this is due to a select few nurses being trained in venesecting, which is more cost effective. Secondly, the questionnaire demonstrated a new problem: the lack of capacity to venesect more patients. This is a rate limiting step in improving venesection services at Barnet General Hospital and requires further research and discussion in feasibility, considering that the medical unit is already running at full capacity.

\section{Conclusion}

This project sought to address a number of issues with the existing venesection service at Barnet General Hospital. The original service consisted of junior doctors, who were neither fully aware of the principles of venesecting, nor were trained. This affected the quality of the service provided. Further issues included increasing delays in discharging patients and staffing shortfalls on the medical wards. Having witnessed how our colleagues at Chase Farm Hospital ran their venesection unit, by using a group of trained nurses, we decided to pose the question of whether this was a feasible option at our medical day unit.

A questionnaire distributed to the existing group of nurses found that $100 \%$ were comfortable with gaining venous access and the main limiting factor was due to a lack of training. When the nurse led service was finally implemented, the capacity of the unit to 
venesect patients increased from four to eight; owing to reduced delays and prompt discharges.

When the questionnaire was redistributed, following the conversion of venesection from a doctor led to a nurse led service, we found that some nurses were unaware of how to deal with complications of venesection. This issue was rectified by further training and an oral presentation, which has been placed on the hospital intranet. Overall though, we noted improved confidence in nurses venesecting, reduced waiting times, and increased patient capacity; all at no extra cost to the trust. Another issue identified for addressing was the potential to further increase the capacity of the unit to venesect, being limited by the number of chairs available. This demonstrates the dynamic changes that occur as a result of a quality improvement project and the potential for further future interventions.

\section{References}

1 Harper A. Cannulation and Venesection. University Hospital Southampton NHS Foundation Trust. http://www.uhs.nhs.uk/Media/suhtideal/TopNavigationArticles/Skills ForPractice/ClinicalSkills/CannulationandVenesectionhandouts.ppt [Accessed 1 June 2015].

2 Royal Berkshire NHS Trust. Having a venesection. http://www.royalberkshire.nhs.uk/patient-informationleaflets/venesection-april-2014.htm [Accessed 1 June 2015].

3 Derby Hospitals NHS Foundation Trust. Venesection.

https://www.derbyhospitals.nhs.uk/easysiteweb/getresource.axd?as setid $=3101$ \&type $=0 \&$ servicetype $=1$ [Accessed 1 June 2015] .

4 Northern Lincolnshire and Goole NHS Foundation Trust. Having a therapeutic venesection.

http://www.nlg.nhs.uk/content/uploads/2014/08/IFP-0810.pdf [Accessed 1 June 2015].

5 Sandra Thurogood. NHS Institute for Innovation and Improvement. Nurse Led Venesection Clinic.

http://www.institute.nhs.uk/hia___other_submissions/other_submissi ons/nurse-led-venesection-clinic.html [Accessed 1 June 2015].

6 Kettering General Hospital NHS Foundation Trust. Therapeutic Venesection.

http://www.kgh.nhs.uk/EasysiteWeb/getresource.axd?AssetID=955 7\&type=Full\&servicetype $=$ Attachment $[$ Accessed 1 June 2015] .

7 East Sussex Healthcare NHS Trust. Venesection Patient Information.

http://www.esht.nhs.uk/EasysiteWeb/getresource.axd?AssetID=272 806\&type=full\&servicetype=Attachment [Accessed 1 June 2015].
8 Science Museum. Bloodletting. Available at: http://www.sciencemuseum.org.uk/broughttolife/techniques/bloodlet ting.aspx. [Accessed 30 May 2015].

9 Markham WO. Venesection in disease. British Medical Journal. May 13 1865: 477. Available at : http://www.ncbi.nlm.nih.gov/pmc/articles/PMC2325670/pdf/brmedj0 5865-0003.pdf. [Accessed 30 May 2015].

10 Blood-letting. British Medical Journal, 1(533), 283-291. March 18, 1871. Available at: http://www.pubmedcentral.nih.gov/pagerender.fcgi?artid=2260507\& pageindex=1\#page. [Accessed 30 May 2015].

11 NICE. Polycythaemia/erythrocytosis Management Guidelines.

http://cks.nice.org.uk/polycythaemiaerythrocytosis\#!scenario [Accessed 1 June 2015].

12 British Society for Haematology. British Committee for Standards in Haematology: Guidelines on diagnosis and therapy.

http://www.bcshguidelines.com/documents/haemochromotosis 200 0.pdf [Accessed 1 June 2015]

13 Ramsey CA, Magnus IA, Turnbull A, Baker $\mathrm{H}$. The treatment of porphyria cutanea tarda by venesection. Quarterly Journal of Medicine. 1 January 1974; 1-24. Available at: http://qjmed.oxfordjournals.org/content/43/1/1. [Accessed 30 May 2015].

14 Davis Jr. WD, Arrowsmith WR. The treatment of hemochromatosis by massive venesection. Annals of Internal Medicine. 1953;39(4):723-734. Available at: http://annals.org/article. aspx?articleid=675405. [Accessed 30 May 2015].

15 Stephens DJ, Kaltreider NL. The therapeutic use of venesection in polycythemia. Annals of Internal Medicine. 1937;10(10):1565-1581. Available at: http://annals.org/article.aspx?articleid=671269. [Accessed 30 May 2015].

\section{Declaration of interests}

Nothing to declare

\section{Acknowledgements}

Dafydd Morgan (Joint first author)

Dr Sylvia Berney (Consultant haematologist)

\section{Ethical approval}

According to trust policy, this project did not require ethical review. 